\title{
Metabolic Fate of the Heart Agent $\left[{ }^{18} \mathrm{~F}\right] 6-$ Fluorometaraminol
}

\author{
KAREN C. ROSENSPIRE, DAVID L. GILDERSLEEVE, \\ CHRISTOPHER C. MASSIN, SURESH G. MISLANKAR \\ and DONALD M. WIELAND*
}

\begin{abstract}
Department of Internal Medicine, Division of Nuclear Medicine, University of Michigan, Ann Arbor,
\end{abstract} MI 48109, U.S.A.

(Received 10 February 1989)

\begin{abstract}
Studies were performed to determine whether $\left[{ }^{18} \mathrm{~F}\right] 6$-fluorometaraminol $\left({ }^{18} \mathrm{~F}\right.$-FMR), a new neuronal heart radiopharmaceutical, is metabolized in vivo and if the metabolites are taken up in heart. Rat, dog, baboon and guinea pig were injected with ${ }^{18}$ F-FMR and tissue samples were analyzed for metabolites by HPLC. Liver contained the most metabolites of the tissues studied with $25-90 \%$ of the radioactivity present as metabolites at $1 \mathrm{~h}$ in all the species studied. While metabolites of ${ }^{18} \mathrm{~F}$-FMR are found in blood, no significant accumulation of these metabolites is found in heart $(\leqslant 0.3 \%) 1 \mathrm{~h}$ after i.v. administration in any species except rat. These studies suggest that ${ }^{18} \mathrm{~F}$-FMR is a suitable agent for quantitative imaging of the heart by positron emission tomography.
\end{abstract}

\section{Introduction}

We have recently described the synthesis of a new heart radiopharmaceutical, $\left[{ }^{18} \mathrm{~F}\right] 6$-fluorometaraminol $\left({ }^{18} \mathrm{~F}-\mathrm{FMR}\right)$, an analog of the false neurotransmitter metaraminol (MR) (Mislankar et al., 1988). Metaraminol is a sympathomimetic amine which has been used clinically as a vasopressor agent with a potency $1 / 20$ th that of norepinephrine (Crout $e t$ al., 1964). Using a canine model of regional heart neuronal damage, positron emission tomography images with ${ }^{18}$ F-FMR clearly delineate neuronal lesions. A high correlation between the concentration of ${ }^{18} \mathrm{~F}$ radioactivity in the heart and tissue norepinephrine levels was obtained (Wieland et al., 1989). Kinetic modeling using PET is possible if the myocardial uptake is due to FMR alone and not metabolites produced elsewhere. The present studies were performed to confirm the suitability of ${ }^{18} \mathrm{~F}-\mathrm{FMR}$ for quantitative PET imaging.

Fluorometaraminol, like MR, should be resistant to enzymatic attack by catechol- $O$-methyltransferase (COMT) and monoamine oxidase (MAO). However, MR itself has been reported to be partially metabolized to $\alpha$-methylnorepinephrine ( $\alpha$-Me-NE) (Fuller et al., 1981b). Studies using pharmacological doses of $M R$ injected intraperitoneally in guinea pigs showed

*All correspondence should be addressed to: Donald $\mathrm{M}$. Wieland, Ph.D., University of Michigan, Phoenix Memorial Laboratory, 2301 Bonisteel Blvd, Ann Arbor, MI 48109-2100, U.S.A. metabolites accounted for $>30 \%$ of the MR-like activity in the heart after $4 \mathrm{~h}$ (Fuller et al., 1981a, b; Maitre and Staehelin, 1965). However, other reports showed little or no metabolites in the hearts of rabbits injected i.v. with pharmacological doses of MR (Gram and Wright, 1966). Thus apparent species differences as well as different routes of administration effect the course of metabolism of MR. We report here a study of the metabolism of ${ }^{18} \mathrm{~F}$-FMR in various animal species.

\section{Materials and Methods}

\section{Synthesis}

$\left[{ }^{18} \mathrm{~F}\right] 6$-Fluorometaraminol was synthesized from 6-acetoxymercurio- $N$ - $t$-BOC-metaraminol and $\left[{ }^{18} \mathrm{~F}\right]$ acetyl hypofluorite as previously described (Mislanker et al., 1988). The final product (sp. act. 1-12 Ci $/ \mathrm{mmol}$; sp. concn $1-4 \mathrm{mCi} / \mathrm{mL}$; radiochemical purity $>92 \%$ ) was dissolved in $0.15 \mathrm{M}$ sodium acetate buffer ( $\mathrm{pH} 4.5)$ for injection.

\section{Animals}

Male and female Sprague-Dawley rats were lightly anesthetized with ethyl ether. Female guinea pigs were anesthesized with ketamine $(30 \mathrm{mg} / \mathrm{kg})$ and xylazine $(5 \mathrm{mg} / \mathrm{kg})$. Mongrel dogs were anesthesized with pentobarbital $(30-35 \mathrm{mg} / \mathrm{kg})$. Animals were injected i.p., i.v. or via the hepatic portal vein with approx. 0.1-1 mCi FMR and sacrificed at time intervals ranging from 5 to $90 \mathrm{~min}$ post injection. A male 
baboon was anesthesized with ketamine $(10-15 \mathrm{mg} / \mathrm{kg})$ and injected with $1 \mathrm{mCi}{ }^{18} \mathrm{~F}$-FMR i.v.; $3 \mathrm{ml}$ antecubital venous blood samples were removed at intervals from 5 to $90 \mathrm{~min}$ post injection. Rat and guinea pig blood samples were obtained from pooled chest blood; antecubital blood samples were obtained from dog.

\section{Tissue preparation for metabolite analysis}

Whole blood samples were prepared for metabolite analysis by adding $1 \mathrm{~mL}$ of heparinized whole blood to $100 \mathrm{mg}$-sulfosalicyclic acid and a few drops of deionized water (Modino et al., 1972). The mixture was vortexed and centrifuged for $2 \mathrm{~min}(12,000 \mathrm{~g}$; ambient temperature).

Plasma was separated from red blood cells by density centrifugation over dibutylphthalate. Heparinized whole blood ( $1 \mathrm{~mL}$ ) was layered on top of $500 \mu \mathrm{L}$ of dibutylphthalate and following a $1 \mathrm{~min}$ centrifugation $(12,000 \mathrm{~g}$; ambient temperature), the plasma was removed and deproteinized with $100 \mathrm{mg} / \mathrm{mL}$ 5-SSA as described above. The density of dibutylphthalate is intermediate to that of red blood cells and plasma and forms a layer between RBC and plasma after centrifugation (Andreasen and Shaumburg, 1974). The advantages of this method over the more traditional triple saline wash method are that less plasma is retained in the RBC layer and less time is required.

Heart and liver samples, after being quickly frozen on dry ice, were minced and homogenized in $3 \mathrm{vol}$ of cold 0.4 M perchloric acid for $20 \mathrm{~s}$ using a Brinkman homogenizer. The homogenate was centrifuged for $5 \mathrm{~min}(12,000 \mathrm{~g}$; room temperature). The supernatant was neutralized with $\mathrm{KOH}$. All supernatants were filtered prior to HPLC analysis and pentanesulfonic acid (PSA) was added to a final concentration of $10 \mathrm{mM}$.

The extraction efficiency (i.e. the \% radioactivity extracted into the supernatant from the tissue) was determined by counting the radioactivity in the supernatant and pellet samples after centrifugation.

\section{Partioning of activity between plasma and $R B C s$}

Whole blood samples from dog $1 \mathrm{~h}$ after injection of ${ }^{18} \mathrm{~F}$-FMR were separated into plasma and RBCs (as described above) and the percent radioactivity in each fraction determined. The radioactive $\mathrm{RBC}$ fraction was incubated at $37^{\circ} \mathrm{C}$ at time intervals from 2 to $5 \mathrm{~min}$ with nonradioactive plasma (taken prior to ${ }^{18}$ F-FMR injection) or phosphate-buffered saline (PBS) (pH 7.4). The samples were separated into plasma or PBS supernatant and RBCs as above and counted for radioactivity.

\section{HPLC analysis}

HPLC analysis was performed using reversedphase ion pair chromatography $[4.6 \times 250 \mathrm{~mm}$ Ultrasphere I.P., Beckman Instruments; solvent A: $25 \mathrm{mM}$ sodium acetate $(\mathrm{pH} 4.75), 10 \mathrm{mM}$ pentanesulfonic acid (PSA); solvent B: $25 \mathrm{mM}$ sodium acetate (pH 4.75), $10 \mathrm{mM}$ PSA and $50 \%$ methanol; flow $=1 \mathrm{~mL} / \mathrm{min}$; linear gradient elution starting at $20 \% \mathrm{~B}$ to $100 \% \mathrm{~B}$ in $20 \mathrm{~min}$ ]. Radioactivity was measured with the Radiomatic FLO-ONE system.

Changes in distribution and metabolism with different routes of administration

Changes in metabolic fate of ${ }^{18}$ F-FMR in heart, blood and liver $1 \mathrm{~h}$ after injection in guinea pigs were investigated using different routes of administration (intravenous, intraperitoneal and hepatic portal). Biodistribution studies were performed in rats 5, 30 and $60 \mathrm{~min}$ after intraperitoneal and intravenous administration of ${ }^{18} \mathrm{~F}$-FMR. Brain, blood, heart and liver were removed following the injection of $100 \mu \mathrm{Ci}$ ${ }^{18}$ F-FMR.

\section{Statistical analysis}

Significance was determined using Student's $t$-test. Data are expressed as means \pm SD.

\section{Results and Discussion}

\section{Distribution of activity between cellular and soluble fraction of blood}

The distribution of radioactivity in whole blood from $\operatorname{dog} 1 \mathrm{~h}$ after the i.v. administration of ${ }^{18} \mathrm{~F}$-FMR shows $21.4 \%(n=2)$ of the activity in plasma with $74.4 \%$ in the RBCs. The remaining $4.3 \%$ of the total blood activity in plasma is acid insoluble. Similar results were obtained at 30 and $90 \mathrm{~min}$ post injection. These results for ${ }^{18} \mathrm{~F}-\mathrm{FMR}$ are in agreement with others using MR (Anton and Berk, 1977) who found $23-34 \%$ of the MR in the plasma and the remainder in $\mathrm{RBC}$ after several hours. Similar results between the dibutylphthalate and saline-washing methods to separate RBC and plasma were obtained. Less than $0.3 \%$ of the radioactivity remained in the dibutylphthalate layer making it a more suitable method than multiple saline washings for rapid separation of plasma.

The radioactivity in the $\mathrm{RBCs}$ is in rapid equilibrium with the activity in the plasma (Table 1). When RBCs that were prelabeled in vivo with ${ }^{18} \mathrm{~F}$. FMR were incubated with nonradioactive plasma, $28 \%$ of the radioactivity redistributed to plasma within $1 \mathrm{~min}$ and remained constant over the next $4 \mathrm{~min}$. Furthermore, the plasma/RBC ratio of activity in vitro is similar to that found in vivo. However, incubating radioactive $\mathrm{RBCs}$ with PBS did not show a release of radioactivity into the PBS (only $8 \%$ in $30 \mathrm{~min}$ ). Factors which are present in plasma but not

Table 1. Partitioning of radioactivity between plasma and $\mathrm{RBC}^{*}$

\begin{tabular}{lcc}
\hline Incubation time & $\%$ in plasma & $\%$ in RBC \\
\hline $1 \min (n=3)$ & $28.2 \pm 2.1$ & $71.8 \pm 2.1$ \\
$5 \min (n=3)$ & $27.9 \pm 1.5$ & $72.2 \pm 1.5$ \\
\hline "Mean \pm SD. & &
\end{tabular}




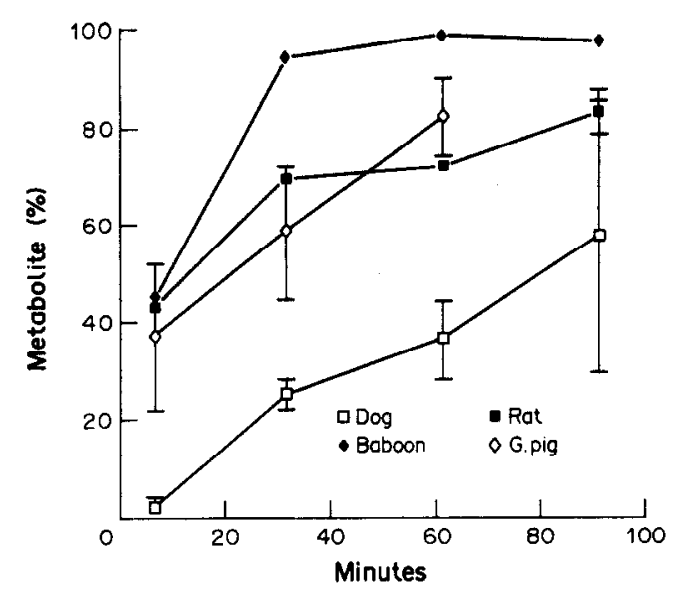

Fig. 1. Metabolites in plasma $(\%$, mean $\pm S D)$ in different species vs time after injection of FMR. Baboon shows metabolites in plasma more rapidly than the other species. Baboon (- - ) 1 animal/time point; dog (- --$)$, rat $(-\square-)$ and guinea pig $(-\diamond-): 3-5$ animals/time point

in PBS are seemingly necessary for release of activity from the RBCs.

\section{Metabolite analysis}

The metabolites of ${ }^{18} \mathrm{~F}$-FMR were studied in plasma, heart and liver of dog, rat and guinea pig; plasma metabolites were studied in baboon. The extraction efficiencies of the radioactivity from the tissue samples into the acid supernatant are $90.8 \pm 0.6,87.2 \pm 2.1$ and $84.2 \pm 1.0$ for plasma, heart and liver (mean \pm SD), respectively. The retention times on HPLC for metabolites are 5-8 min compared to ${ }^{18} \mathrm{~F}$-FMR which elutes at $21 \mathrm{~min}$. Metabolites appear in the plasma of the baboon more rapidly than dog or rat (Fig. 1). The results obtained in guinea pig are similar to baboon. Numerous studies have reported species differences in the metabolism of MR in several different tissues, with the guinea pig metabolizing the drug more than rat or rabbit (Fuller et al., 1981b; Gram and Wright, 1965, 1966; Maître and Staehelin, 1965).

Comparing whole blood and plasma supernatants in dogs at $30-90 \mathrm{~min}$, it is noted that whole blood has more unmetabolized ${ }^{18} \mathrm{~F}$-FMR $(88-95 \%)$ than plasma $(64-73 \%)$ suggesting that the activity contained in the RBCs is principally in the form of unmetabolized ${ }^{18}$ F-FMR.
HPLC analysis of heart extracts from dog and guinea pig showed virtually no metabolites $(98-100 \%$ as ${ }^{18} \mathrm{~F}$-FMR) $1 \mathrm{~h}$ after injection (Table 2). In rat, however, metabolites account for $18 \%$ of the radioactivity in the heart. These results are in contrast to previous studies showing no metabolites of MR in rat heart (Fuller et al., 1981b). However, they injected large amounts of MR subcutaneously $(5 \mathrm{mg} / \mathrm{kg})$; in the present study, we injected ${ }^{18} \mathrm{~F}$-FMR intravenously at tracer levels $(<1 \mathrm{mg} / \mathrm{kg})$.

Liver showed more metabolites of ${ }^{18} \mathrm{~F}$-FMR with $62 \%$ as ${ }^{18} \mathrm{~F}$ metabolites in guinea pig, $26 \%$ in dog and $82 \%$ in rat after $1 \mathrm{~h}$ (Table 2). Dog urine contained very few metabolites, with a majority of the activity excreted as ${ }^{18}$ F-FMR $(86-98 \%)$ at 30 and $60 \mathrm{~min}$ after injection.

While not identified, the metabolites found in the tissues are thought to be 6-F- $\alpha$-methyl-norepinephrine ( $\alpha-\mathrm{F}-\mathrm{Me}-\mathrm{NE})$ and/or its $O$-methyl derivative $\alpha$-methyl-normetanephrine. Previous studies had found considerable levels of $\alpha$-Me-NE in guinea pig hearts $4 \mathrm{~h}$ after intraperitoneal MR administration with about equal levels of MR and $\alpha$-Me-NE in liver (Fuller et al., 1981b). It has been suggested that MR can be $p$-hydroxylated to $\alpha$-Me-NE followed by 3- $O$-methylation to form $\alpha$-methyl-normetanephrine in the guinea pig, but that there may be species differences in the rates of these reactions (Maitre and Staehelin, 1965; Fuller et al., 1981a). The in vivo formation of $\alpha$-methyl-normetanephrine was observed, but it was not retained by mouse heart (Carlsson et al., 1967). Such species differences may account for the metabolite pattern of ${ }^{18} \mathrm{~F}$-FMR we observed in blood and liver of guinea pig, rat and dog. Since metabolism of ${ }^{18} \mathrm{~F}-\mathrm{FMR}$ primarily occurs at the 3 and 4 positions it would be extremely interesting to study 4-fluorometaraminol since the formation of metabolites may be even further restricted.

\section{Effect of different routes of administration on distribution}

Table 3 shows the results of a biodistribution study in guinea pigs after administration of ${ }^{18} \mathrm{~F}$-FMR via an i.p. or i.v. injection. After an i.v. injection, radioactivity is rapidly cleared from the blood while uptake into the liver and heart is rapid. Activity in the heart remains fairly constant. However, after an i.p. injection, the activity in the blood remains low; the

Table 2. Percent ${ }^{18} \mathrm{~F}$ activity as ${ }^{18} \mathrm{~F}$-FMR for heart and liver

\begin{tabular}{|c|c|c|c|c|c|c|}
\hline \multirow{2}{*}{$\begin{array}{l}\text { Time } \\
(\min )\end{array}$} & \multicolumn{2}{|c|}{ Guinea pig $\dagger$} & \multicolumn{2}{|c|}{ Dog } & \multicolumn{2}{|c|}{ Rat } \\
\hline & Heart & Liver & Heart & Liver & Heart & Liver \\
\hline $\begin{array}{r}5 \\
30 \\
60\end{array}$ & $\begin{array}{l}96.5 \pm 2.1(2) \\
93.1 \pm 3.9(3) \\
99.8 \pm 0.4(4)\end{array}$ & $\begin{array}{l}80.6 \pm 4.2(2) \\
62.2 \pm 10.2(2) \\
38.5 \pm 4.0(3)\end{array}$ & $\begin{array}{c}\text { ND‡ } \\
\text { ND } \\
99.8 \pm 0.3(2)\end{array}$ & $\begin{array}{c}\text { ND } \\
\text { ND } \\
73.6 \pm 12.4(2)\end{array}$ & $\begin{array}{c}\text { ND } \\
\text { ND } \\
81.6 \pm 9.0(4)\end{array}$ & $\begin{array}{c}\text { ND } \\
\text { ND } \\
10.8 \pm 0.3(2)\end{array}$ \\
\hline
\end{tabular}


Table 3. Distribution of ${ }^{18} \mathrm{~F}$-activity in rats

\begin{tabular}{llll}
\hline & \multicolumn{1}{c}{$5 \mathrm{~min}$} & \multicolumn{1}{c}{$30 \mathrm{~min}$} & \multicolumn{1}{c}{$60 \mathrm{~min}$} \\
\hline $\begin{array}{l}\text { i.p. Injection } \\
\text { Blood }\end{array}$ & $0.01 \pm 0.001$ & $0.03 \pm 0.001$ & $0.03 \pm 0.003$ \\
Heart & $0.05 \pm 0.01$ & $0.23 \pm 0.02$ & $0.24 \pm 0.02$ \\
Liver & $0.32 \pm 0.07$ & $0.64 \pm 0.05$ & $0.55 \pm 0.07$ \\
i.v. Injection & & & \\
Blood & $0.03 \pm 0.001$ & $0.03 \pm 0.001$ & $0.02 \pm 0.001$ \\
Heart & $0.56 \pm 0.05$ & $0.51 \pm 0.06$ & $0.45 \pm 0.12$ \\
Liver & $0.44 \pm 0.03$ & $0.40 \pm 0.09$ & $0.33 \pm 0.05$ \\
\hline
\end{tabular}

*Percent $\mathrm{kg}$ dose $/ \mathrm{g}$; Mean $\pm \mathrm{SD}$ (three animals/time point).

concentration of activity in the heart is lower than after an i.v. injection and takes longer $(30 \mathrm{~min})$ to reach its maximum.

It is known that the route of administration of $\mathrm{a}$ drug can alter the biodistribution and metabolism of a drug (Benet, 1978). The preferable route of administration of ${ }^{18} \mathrm{~F}$-FMR would be intravenous. However, previous studies of MR metabolism used either intraperitoneal or subcutaneous injections (Fuller et al., 1981a, b; Anton and Berk, 1977; Maître and Staehelin, 1965). After i.p. injection, drugs are absorbed into the circulation via the mesenteric vascular bed and are then transported directly to the liver via the hepatic portal system where extensive metabolism may occur before reaching the heart.

\section{Effect of different routes of administration on metabolism}

The metabolite study in guinea pigs (Table 4) indicates there are more metabolites in heart after an intraperitoneal injection (23\%) than after an hepatic portal $(10 \%)$ or i.v. injection $(<1 \%)$. The liver may produce more ${ }^{18} \mathrm{~F}$-FMR metabolites from an i.p. or hepatic portal vein injection because the first pass metabolism by liver is greater than from an intravenous injection. This may explain the increase in metabolites we observed in heart from an intraperitoneal or hepatic portal injection compared to an intravenous injection. Liver metabolism can form $\alpha-\mathrm{Me}-\mathrm{NE}$ in vitro, and the liver and heart contained maximal levels of both MR and its metabolite $\alpha$-MeNE 4 h after i.p. administration of MR (Fuller et al., $1981 \mathrm{~b})$. Thus the route of administration greatly affects the distribution of the ${ }^{18} \mathrm{~F}-\mathrm{FMR}$ and its metabolites.

In summary, the results of this study show that ${ }^{18} \mathrm{~F}-\mathrm{FMR}$ is an ideal agent for quantitative imaging of the neurons of the myocardium. Intravenously administered FMR has been shown to be highly extracted and retained by heart (Hutchins et al., 1988). We have shown that ${ }^{18}$ F-FMR distribution and

Table 4. Percent metabolite from ${ }^{18}$ F-FMR in guinea pigs $(t=60 \mathrm{~min})($ mean $\pm \mathrm{SD})$

\begin{tabular}{lccc}
\hline & $\begin{array}{c}\text { Heart } \\
\text { (\% metabolite) }\end{array}$ & $\begin{array}{c}\text { Plasma } \\
\text { (\% metabolite) }\end{array}$ & $\begin{array}{c}\text { Liver } \\
\text { (\% metabolite) }\end{array}$ \\
\hline i.v. $(n=3)$ & $0.3 \pm 0.4$ & $85.0 \pm 3.9$ & $61.5 \pm 4.0$ \\
i.p. $(n=2)$ & $22.9 \pm 9.6$ & $55.3 \pm 22.9$ & $57.1 \pm 2.1$ \\
HPV* $(n=3)$ & $9.7 \pm 4.3$ & $93.3 \pm 6.0$ & $79.0 \pm 8.2$ \\
\hline
\end{tabular}

HPV = hepatic portal vein. metabolism is highly dependent on the species and route of administration thus making it difficult to compare our studies of ${ }^{18} \mathrm{~F}$-FMR to those reported for MR. Although metabolites of ${ }^{18}$ F-FMR are produced and found in the blood, no significant uptake of metabolites are found in the heart after i.v. administration of ${ }^{18}$ F-FMR. Thus, kinetic modeling of ${ }^{18}$ F-FMR heart uptake should be possible. The blood activity curve which is used as the input function for kinetic modeling can be generated from whole blood rather than plasma, since the ${ }^{18} \mathrm{~F}$-FMR is in rapid equilibrium beween the plasma and RBC components. In addition, since the blood activity curve can be corrected for metabolites, a more accurate estimation of the neuronal localization of ${ }^{18} \mathrm{~F}$-FMR using quantitative PET imaging can be made. However, species differences in metabolism of ${ }^{18} \mathrm{~F}$ FMR require that the blood activity curve corrections be determined for each species under study.

Acknowledgements - We thank the staff of the University of Michigan Cyclotron/P.E.T. Facility for their assistance in providing ${ }^{18} \mathrm{~F}$; Phillip Sherman, Teresa Pisani and Ngoc Nuygen of the Biodistribution Laboratory for their valuable assistance in the animal studies; Phoenix Memorial Laboratory for laboratory space; and Linder Markham for typing the manuscript. This work was funded by NIH Grant HL27555.

\section{References}

Andreasen, P. A.; Schaumburg, B. P. A rapid technique for the separation of thymocytes from suspension by centrifugation through silicon oil. Anal. Biochem. 59: 610-616; 1974.

Anton, A. H.; Berk, A. I. Distribution of metaraminol and its relation to norepinephrine. Eur. J. Pharmacol. 44: 161-167; 1977.

Benet, L. Z. Effect of route of administration and distribution on drug action. J. Pharmacokinetic Biopharm. 6: 559-585; 1978.

Carlsson, A.; Lundborg, P.; Stitzel, R.; Waldeck, B. Uptake, storage and release of ${ }^{3} \mathrm{H}-\alpha$-methyl-norepinephrine. $J$. Pharmacol. Exp. Ther. 158: 175-182; 1967.

Crout, J. R.; Alpers, H. S.; Tatum, E. L.; Shore, P. A. Release of metaraminol (Aramine) from the heart by sympathetic nerve stimulation. Science 145: 828-829; 1964.

Fuller, R. W.; Snoddy, H. D.; Perry, K. W. Tissue levels of metaraminol and its metabolite, $\alpha$-methylnorepinephrine, in control and 6-hydroxydopamine-pretreated guinea pigs. Life Sci. 29: 1271-1275; 1981a.

Fuller, R. W.; Snoddy, H. D.; Perry, K. W.; Bernstein, J. R.; Murphy, P. J. Formation of $\alpha$-methylnorepinephrine as a metabolite of metaraminol in guinea pigs. Biochem. Pharmacol. 30: 2831-2836; 1981 b.

Gram, T. E; Wright, H. N. Lack of metaraminol biotransformation by rabbit tissues in vitro. Biochem. Pharmacol. 14: 1911-1914; 1965.

Gram, T. E.; Wright, H. N. Some factors influencing the action of metaraminol in rabbits. Arch. Int. Pharmacodyn. 160: 294-311, 1966.

Hutchins, G. D.; Rothley, J. M.; Wieland, D. M.; Rosenspire, K. C.; Kuhl, D. E.; Schwaiger, M. Evaluation of 6-[F-18]fluorometaraminol (FMR) kinetics in canine myocardium using positron emission tomography. $J$. Nucl. Med. 29: 907; 1988.

Maître, L.; Staehelin, M. Presence of $\alpha$-methyl-noradrenaline ("Corbasil") in the heart of guinea-pigs treated 
with metaraminol ("Aramine"). Nature 206: 723-724; 1965.

Mislankar, S. G.; Gildersleeve, D. L.; Wieland, D. M.; Massin, C. C.; Mulholland, G. K.; Toorongian, S. A. $\left[{ }^{18} \mathrm{~F}\right] 6$-Fluorometaraminol: a radiotracer for in vivo mapping of adrenergic nerves of the heart. J. Med. Chem. 31: 362-366; 1988.

Modino, A.; Bongioranni, G.; Fumero, S.; Rossi, L. An improved method of plasma deproteination with sulphosalicylic acid for determining amino acids and related compounds. J. Chromatogr. 74: 255-263; 1972.

Wieland, D. M.; Rosenspire, K. C.; Hutchins, G. D.; Mislankar, S. G.; Lee, H. T.; Massin, C. C.; Gildersleeve, D. L.; Rothley, J. M.; Sherman, P. S.; Schwaiger, M. Neuronal mapping of the heart with 6-[18F]luorometaraminolo. J. Med. Chem. In press; 1989. 